\title{
Prophylactic tricuspid repair: The battle is lost, but the war is not over
}

\author{
Nicholas R. Teman, MD, and Gorav Ailawadi, MD
}

\footnotetext{
From the Division of Thoracic and Cardiovascular Surgery, Department of Surgery, University of Virginia Health System, Charlottesville, Va.

Disclosures: G.A. reports modest consulting fees from Abbot Vascular, Mitralign, and Edwards; and modest speaker fees from St Jude Medical. N.R.T. has nothing to disclose with regard to commercial support.

Received for publication Feb 23, 2018; accepted for publication Feb 27, 2018; available ahead of print April 10, 2018.

Address for reprints: Gorav Ailawadi, MD, Division of Thoracic and Cardiovascular Surgery, Department of Surgery, University of Virginia, PO Box 800679, Charlottesville, VA 22903 (E-mail: Gorav@ virginia.edu). J Thorac Cardiovasc Surg 2018;155:2437-8

$0022-5223 / \$ 36.00$

Copyright (c) 2018 by The American Association for Thoracic Surgery

https://doi.org/10.1016/j.jtcvs.2018.02.067
}

Current American Heart Association/American College of Cardiology and European Society of Cardiology/European Association for Cardio-Thoracic Surgery guidelines for the management of valvular disease give a Class IIa recommendation to performing a tricuspid valve repair in patients with tricuspid annular size greater than $40 \mathrm{~mm}$ at the time of leftsided valve surgery, regardless of the degree of tricuspid regurgitation (TR). ${ }^{1,2}$ In the current issue of the Journal, David and colleagues ${ }^{3}$ challenge the assumption that unaddressed tricuspid annular dilatation is associated with the development of TR. In their single-center retrospective review of 312 patients undergoing mitral valve repair, they found no association between the size of the tricuspid annulus and the subsequent development of TR.

Although this finding is thought provoking, there are several important points that should be considered before using this study as justification for a change in practice. This is a retrospective study in which patients who underwent concomitant tricuspid valve repair were excluded. The annular size in these patients is not known, and it is possible that patients with an enlarged tricuspid annulus who would have progressed to worse TR already underwent operation and were excluded from this study. Another important limitation is that the measurements of tricuspid annular size were performed intraoperatively using transesophageal echocardiography under general anesthesia. In contrast, the Current American Heart Association/American College of Cardiology guidelines for tricuspid size are based on transthoracic echocardiography or direct intraoperative measurement.

The pathophysiology of secondary TR is often due to dilation of the tricuspid annulus. Multiple previous echocardiographic studies have shown an association between an enlarged tricuspid annulus and TR. ${ }^{4,5}$ Repair of severe TR associated with a dilated tricuspid annulus is widely accepted, but the management of the dilated annulus without TR is more controversial. In their classic study,

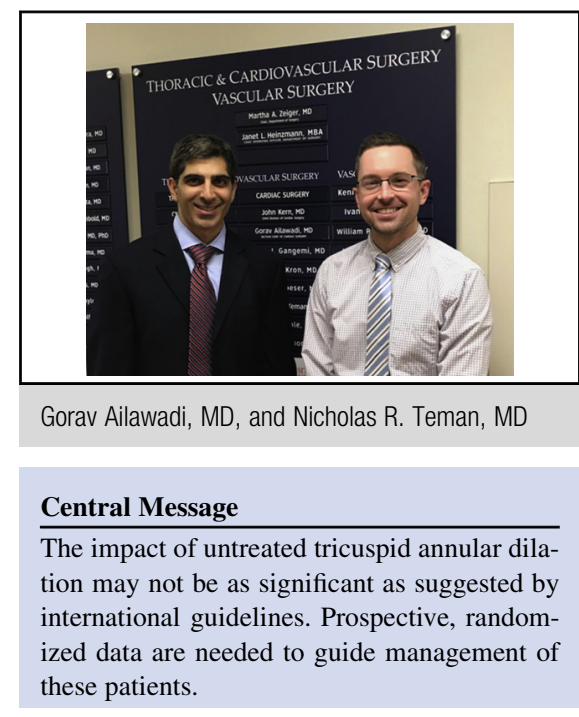

See Article page 2429.

Dreyfus and colleagues ${ }^{6}$ demonstrated that patients with an intraoperative tricuspid annulus size of $70 \mathrm{~mm}$ or greater had improved functional status and tricuspid function when a tricuspid repair was performed, even though the majority of those patients did not have evidence of significant TR preoperatively. David and colleagues ${ }^{3}$ acknowledge these results, but argue that similar data do not exist to support the empiric repair of tricuspid valves with annulus size of $40 \mathrm{~mm}$ or greater as recommended by the guidelines. Several other studies have suggested a benefit to prophylactic tricuspid repair. ${ }^{7-10}$ In another retrospective analysis, Chikwe and colleagues ${ }^{7}$ have reported greater freedom from moderate TR when the tricuspid valve is repaired in the setting of tricuspid annular dilation. Teman and colleagues ${ }^{10}$ found that patients who had their tricuspid disease addressed at the time of mitral valve surgery had superior outcomes when compared with those in a propensitymatched group who later required redo surgery for residual TR, emphasizing the significant morbidity and mortality associated with redo tricuspid valve surgery.

The current study does not provide any comparative outcome data for patients with a dilated tricuspid annulus, and thus the question remains of how to manage these patients. The Cardiothoracic Surgical Trials Network is currently enrolling patients in a trial that hopes to clarify this issue. ${ }^{11}$ Patients undergoing a mitral valve procedure for degenerative MR with moderate TR or tricuspid dilation 
greater than $40 \mathrm{~mm}$ are randomized to mitral surgery with or without tricuspid repair. This trial will be a landmark study that will enhance the plethora of single institution retrospective studies on this controversial clinical dilemma and will hopefully add guidance to the best approach to treat the tricuspid valve.

\section{References}

1. Nishimura RA, Otto CM, Bonow RO, Carabello BA, Erwin JP III, Guyton RA, et al; ACC/AHA Task Force Members. 2014 AHA/ACC guideline for the management of patients with valvular heart disease: executive summary: a report of the American College of Cardiology/American Heart Association task force on practice guidelines. Circulation. 2014;129:2440-92.

2. Falk V, Baumgartner H, Bax JJ, De Bonis M, Hamm C, Holm PJ, et al; ESC Scientific Document Group. 2017 ESC/EACTS guidelines for the management of valvular heart disease. Eur J Cardiothorac Surg. 2017;52:616-64.

3. David TE, David CM, Manlhiot C. Tricuspid annulus diameter does not predict the development of tricuspid regurgitation after mitral valve repair for mitral regurgitation due to degenerative diseases. J Thorac Cardiovasc Surg. 2018;155:2429-36.

4. Come PC, Riley MF. Tricuspid annular dilatation and failure of tricuspid leaflet coaptation in tricuspid regurgitation. Am J Cardiol. 1985;55:599-601.
5. Fukuda S, Gillinov AM, Song JM, Daimon M, Kongsaerepong V, Thomas JD, et al. Echocardiographic insights into atrial and ventricular mechanisms of functional tricuspid regurgitation. Am Heart J. 2006;152:1208-14.

6. Dreyfus GD, Corbi PJ, Chan KM, Bahrami T. Secondary tricuspid regurgitation or dilatation: which should be the criteria for surgical repair? Ann Thorac Surg. 2005;79:127-32.

7. Chikwe J, Itagaki S, Anyanwu A, Adams DH. Impact of concomitant tricuspid annuloplasty on tricuspid regurgitation, right ventricular function, and pulmonary artery hypertension after repair of mitral valve prolapse. J Am Coll Cardiol. 2015;65:1931-8.

8. Benedetto U, Melina G, Angeloni E, Refice S, Roscitano A, Comito C, et al. Prophylactic tricuspid annuloplasty in patients with dilated tricuspid annulus undergoing mitral valve surgery. J Thorac Cardiovasc Surg. 2012; $143: 632-8$.

9. Van de Veire NR, Braun J, Delgado V, Versteegh MI, Dion RA, Klautz RJ, et al. Tricuspid annuloplasty prevents right ventricular dilatation and progression of tricuspid regurgitation in patients with tricuspid annular dilatation undergoing mitral valve repair. J Thorac Cardiovasc Surg. 2011;141:1431-9.

10. Teman NR, Huffman LC, Krajacic M, Pagani FD, Haft JW, Bolling SF. "Prophylactic" tricuspid repair for functional tricuspid regurgitation. Ann Thorac Surg. 2014;97:1520-4.

11. Evaluating the benefit of concurrent tricuspid valve repair during mitral surgery. Available at: https://clinicaltrials.gov/show/NCT02675244. Accessed February $16,2018$. 